\title{
Progressive multifocal cerebral infarction from intravascular large B cell lymphoma presenting in a man: a case report
}

\author{
Pornpong Jitpratoom¹, Patcharawan Yuckpan ${ }^{1}$, Panitta Sitthinamsuwan², Wattanachai Chotinaiwattarakul', \\ Yingyong Chinthammitr ${ }^{1 *}$
}

\begin{abstract}
Introduction: Intravascular lymphoma is rare, and may present as ischemic stroke. Diagnosis is difficult due to the non-specific presentation and lack of lymphadenopathy, thus leading to frequent instances of autopsy-proven diagnosis. To the best of our knowledge, this is the first report of progressive stroke from intravascular lymphoma diagnosed antemortem by random skin biopsy.

Case presentation: A 42-year-old Thai man presented to our hospital with progressive multifocal cerebral infarction. Despite taking aspirin (300 mg/day), his neurological symptoms worsened. During admission, he developed an unexplained fever and hypoxemia. Magnetic resonance angiography clearly showed patency of all cerebral arteries including the internal carotid and vertebrobasilar arteries. Echocardiography, an antiphospholipid antibody test, cerebrospinal fluid cytology and a bone marrow study were normal. Other laboratory test results showed an elevated lactate dehydrogenase level, nephrotic range proteinuria (3.91 g/day), hypoalbuminemia $(1.9 \mathrm{~g} / \mathrm{dL})$, a very low high-density lipoprotein level $(7 \mathrm{mg} / \mathrm{dL})$ and hypertriglyceridemia (353 mg/dL). Because of suspected vasculitis, pulse methylprednisolone was given with transiently minimal improvement. A random skin biopsy from both thighs revealed intravascular large B cell lymphoma. Chemotherapy was not given due to our patient having ventilator associated pneumonia. He died 10 days after the definite diagnosis was established.
\end{abstract}

Conclusion: One etiology of stroke is intravascular lymphoma, in which random skin biopsy can be helpful for antemortem diagnosis.

\section{Introduction}

Intravascular lymphoma (IVL) is a rare type of extranodal lymphoma with an aggressive clinical course characterized by proliferation of lymphoma cells within the lumina of vessels, particularly the capillaries, with the exception of large arteries and veins [1,2]. Because of its varied clinical symptoms and the absence of lymphadenopathy, a diagnosis of IVL is extremely difficult to make and many of the reported cases were diagnosed postmortem. We report the case of a 42-year-old man with IVL who presented with the clinical features of progressive multifocal cerebral infarction.

\footnotetext{
* Correspondence: dryingyong@gmail.com

'Department of Medicine, Faculty of Medicine, Siriraj Hospital, Mahidol University, Bangkok, Thailand

Full list of author information is available at the end of the article
}

\section{Case presentation}

A 42-year-old previously healthy Thai man developed slow ataxia, motor aphasia and frontal lobe releasing signs, gradually progressing over two months. A computed tomography $(\mathrm{CT})$ scan of the brain showed multiple hypodensity lesions at bilateral occipito-parieto-frontal and cerebellar regions consistent with cerebral infarction (Figure 1). Our patient was treated with aspirin, $300 \mathrm{mg} /$ day. His echocardiography results were unremarkable. A complete blood count $(\mathrm{CBC})$ showed only mild anemia (hemoglobin $(\mathrm{Hb}) 10.1 \mathrm{~g} / \mathrm{dL}$, mean corpuscular volume $80 \mathrm{fL}$, white blood cell count 6270 cells $/ \mathrm{mm}^{3}$, platelet count 192,000 cells $/ \mathrm{mm}^{3}$; neutrophils $72 \%$, lymphocytes $17 \%$, monocytes $11 \%$ ). Antiphospholipid antibody (lupus anticoagulant, anticardiolipin antibodies, anti-B2GP1 antibodies), antinuclear antibody (ANA), and Venereal Disease Research Laboratory (VDRL) tests were

\section{Biomed Central}




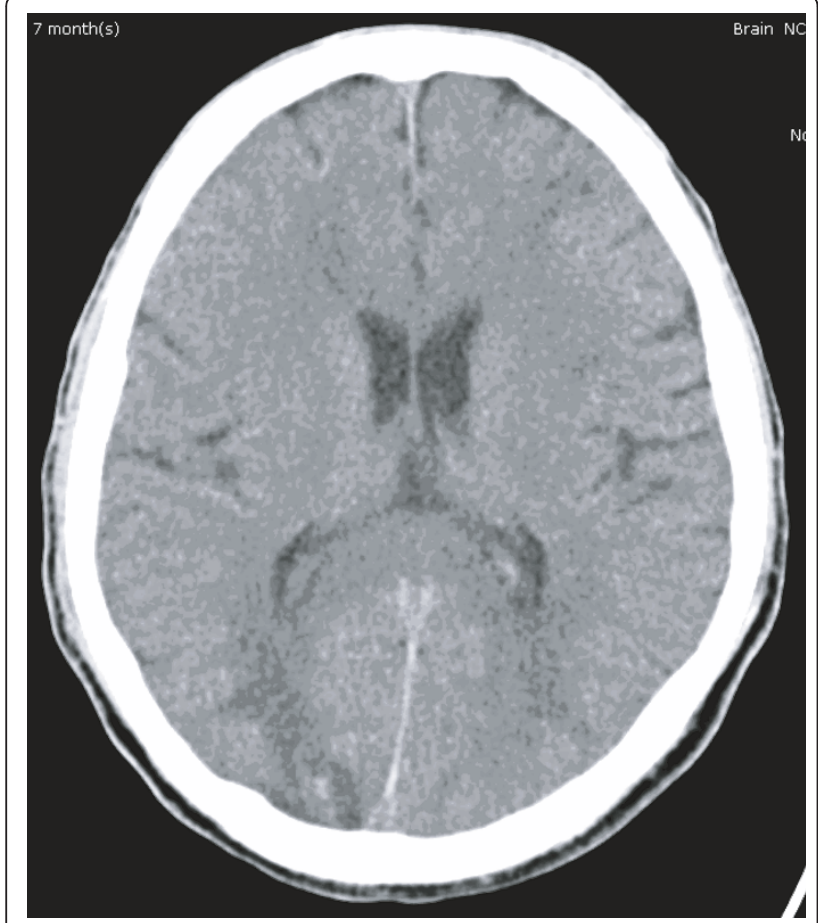

Figure 1 Computed tomography scan of the brain (with contrast) showing ill-defined hypodensity lesion with multiple hypodensity spots at bilateral parieto-occipito-temporal regions. The lesion was more on the right than the left cerebral hemisphere.

negative. Other laboratory test results showed an erythrocyte sedimentation rate (ESR) of $89 \mathrm{~mm} /$ hour, a C-reactive protein (CRP) level of $64 \mathrm{mg} / \mathrm{L}$, and a lactate dehydrogenase (LDH) level of $873 \mathrm{U} / \mathrm{L}$ (normal range 225 to $450 \mathrm{U} / \mathrm{L})$. Within two weeks his neurological condition had deteriorated, as noted by developing left hemiplegia and a worsening level of consciousness. Concurrently, he had developed low-grade fever without an identifiable source of infection and an elevated level of LDH (1203 U/L). A repeat CBC still showed only anemia (Hb $8.5 \mathrm{~g} / \mathrm{dL}$, WBC count 8220 cells $/ \mathrm{mm}^{3}$, platelets 160,000 cells $\left./ \mathrm{mm}^{3}\right)$. He also had unexplained hypoxemia $\left(\mathrm{PaO}_{2} 59.5 \mathrm{mmHg}, \mathrm{O}_{2}\right.$ saturation 92\%, $\mathrm{PaCO}_{2}$ $35.9 \mathrm{mmHg}$ ). Doppler ultrasound scans of the veins of both legs were normal. Intravascular lymphoma was suspected. A bone marrow study showed normal marrow with no evidence of hemophagocytosis and lymphoma involvement on both hematoxylin and eosin and immunohistochemical staining. Because a bone marrow study and cerebrospinal fluid cytology showed unremarkable results, we decided to perform a random skin biopsy on both thighs. A magnetic resonance imaging (MRI) scan of the brain showed diffuse multistage intraparenchymal infarctions and hemorrhages in the bilateral cerebral and cerebellar hemispheres (Figure 2). However, magnetic

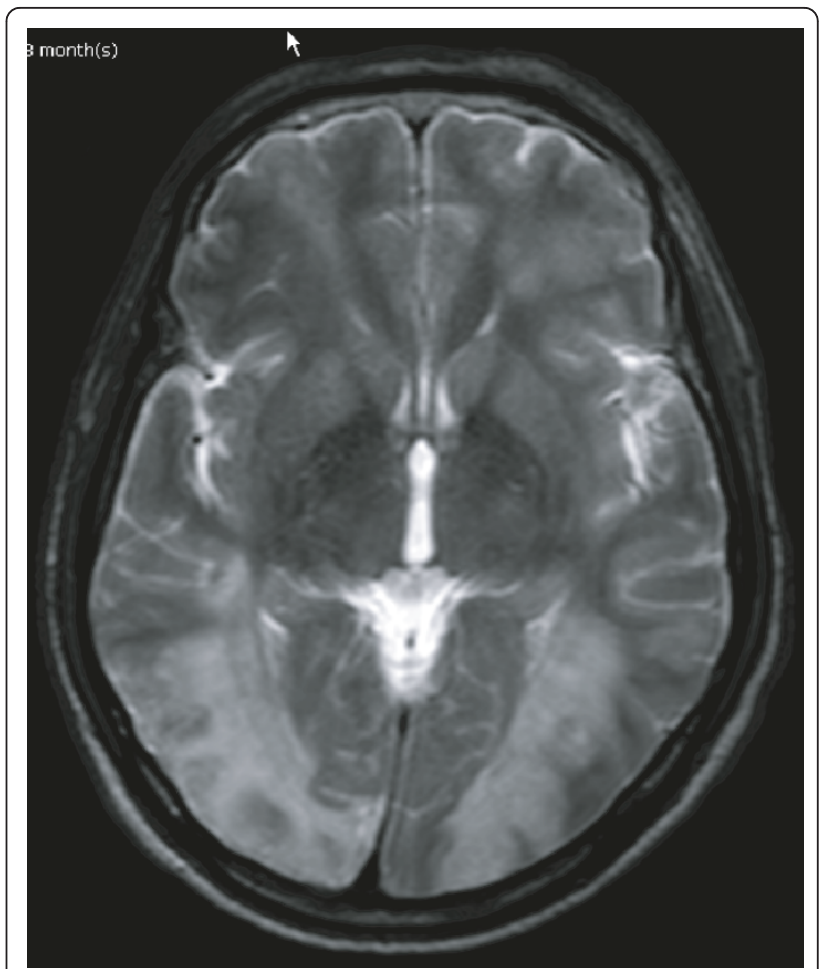

Figure 2 MRI scan of the brain demonstrating diffuse multistage intraparenchymal infarction and hemorrhage at both cerebral and cerebellar hemispheres, initially considered to be vasculitis

resonance angiography (MRA) of the brain revealed normal intracranial vasculature (Figure 3 ). Vasculitis was considered, so our patient was treated with pulse methylprednisolone ( $1 \mathrm{~g} /$ day for five days), with his clinical symptoms partially improving as a result. Interestingly, the pathological findings of the random skin biopsies showed intravascular large B cell lymphoma (IVBL, positive for CD20) (Figure 4). He also had nephrotic range proteinuria (24-hour urine protein was $3.91 \mathrm{~g}$ ), hypoalbuminemia (1.9 g/dL), hypertriglyceridemia $(353 \mathrm{mg} / \mathrm{dL})$ and very low high-density lipoprotein (HDL) $(7 \mathrm{mg} / \mathrm{dL})$. We planned to start our patient on chemotherapy but he developed septic shock from ventilator associated pneumonia and died on the 10th day after the definitive diagnosis.

\section{Discussion}

The clinical presentation of IVBL is variable, but the disease has a fulminant course that confers a poor prognosis. Patients may present with a spectrum of symptoms ranging from pyrexia and non-specific constitutional symptoms to multi-organ failure $[3,4]$. The most common clinical manifestations involve the nervous system and the skin, with at least $68 \%$ of patients having involvement of at least one of these organs [4]. Other reported clinical 


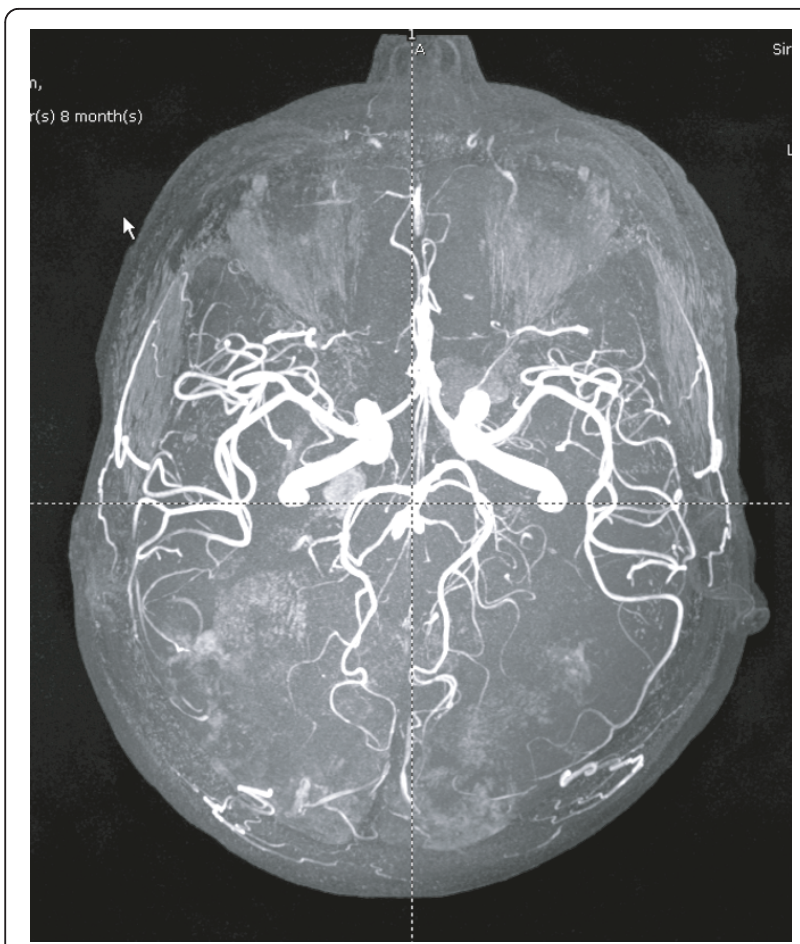

Figure 3 Magnetic resonance angiogram of the brain demonstrating normal patency of bilateral internal carotid arteries, anterior cerebral arteries, middle cerebral arteries, posterior cerebral arteries, and vertebrobasilar arteries. manifestations included fever of unknown origin [4], hypoxemia [5], nephrotic syndrome [6], hemophagocytic syndrome [7], arthritis [8], and myocardial infarction [9]. Anemia and elevated lactate dehydrogenase ( $\mathrm{LDH})$ were the most common laboratory findings [3]. The clinical diagnosis of IVL is challenging and often difficult to diagnose antemortem, and the poor prognosis for these patients reflects delays in diagnosis and the institution of chemotherapy. Use of random skin biopsy was reported to help diagnose IVL antemortem [10-12].

Our patient presented with neurological manifestations but did not have cutaneous involvement of IVBL. Initial laboratory abnormalities included mild anemia and elevated LDH, which were non-specific for IVL. Other laboratory test results related to IVL, such as soluble interleukin 2 receptor level [12] and serum ferritin level tests, were not performed. There was no evidence of hemophagocytic syndrome from a bone marrow study. However, histological evidence of IVBL in skin biopsies taken from apparently normal skin has been documented previously. A skin biopsy enabled diagnosis of IVBL in our patient.

The neurological manifestations of IVBL are varied, ranging from focal ischemic events to dementia [3]. Ischemic stroke is a common disease worldwide and is mostly caused by atherosclerotic arterial disease. However, our patient showed some symptoms that

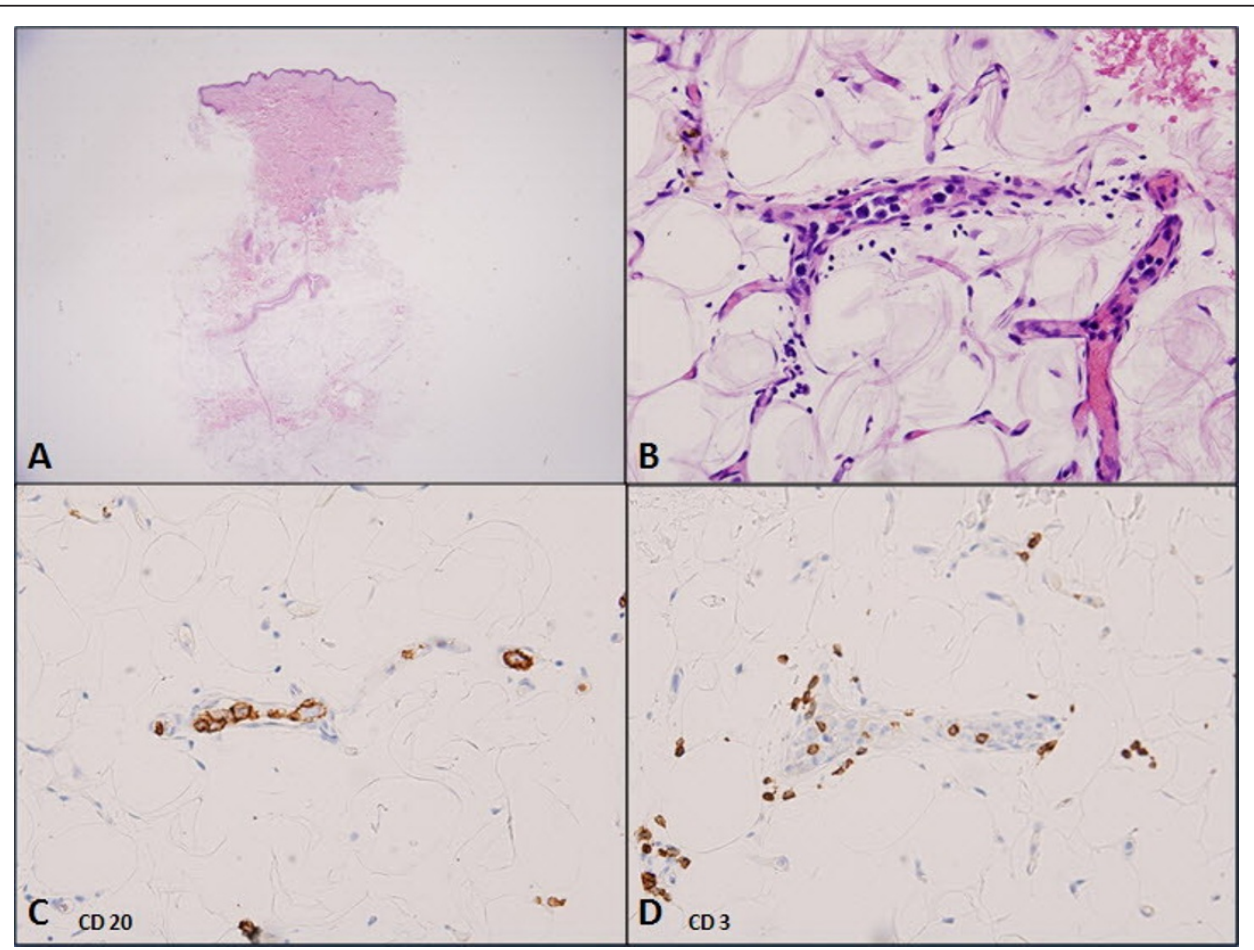

Figure 4 Skin biopsy. A) Low magnification showed no apparent diagnostic abnormality (hematoxylin and eosin stain, $40 \times$ magnification). B) High magnification revealed a few large lymphoma cells in the lumens of capillaries in subcutaneous fat (hematoxylin and eosin stain, $400 \times$ magnification). C) Large lymphoma cells marked with CD20. D) Scattered CD3+ small lymphocytes were noted among the large lymphoma cells. Copyright 2005 Blackwell Publishing Ltd. Reproduced with permission. 
guided us to consider IVL as more likely than atherosclerotic arterial disease: our patient had no apparent atherosclerotic risk factor and there was no evidence of a cardiac source of emboli and antiphospholipid syndrome, aspirin did not retard the progression of stroke, he developed an unexplained fever in the second week of hospitalization without an identifiable source of infection and the fever did not respond to empirical antibiotics, he developed unexplained hypoxemia, his serum LDH was elevated to $1203 \mathrm{U} / \mathrm{L}$, he had unexplained nephrotic range proteinuria, hypoalbuminemia and hypertriglyceridemia, and finally, MRA showed normal intracranial arteries.

\section{Conclusion}

Even though intravascular lymphoma is uncommon, the disease should be considered in the differential diagnosis of neurological manifestations or fever of unknown origin with elevated level of lactate dehydrogenase. Our patient's case shows that a random skin biopsy from normal skin can help a physician to diagnose IVBL. We recommend random skin biopsy, a safe bedside procedure, be used in the evaluation of patients in whom the diagnosis of IVL is doubtful, particularly before other invasive investigations are used.

\section{Consent}

Written informed consent was obtained from the patient's next of kin for publication of this case report and any accompanying images. A copy of the written consent is available for review by the Editor-in-Chief of this journal.

\footnotetext{
Author details

${ }^{1}$ Department of Medicine, Faculty of Medicine, Siriraj Hospital, Mahidol University, Bangkok, Thailand. ${ }^{2}$ Department of Pathology, Faculty of Medicine, Siriraj Hospital, Mahidol University, Bangkok, Thailand.
}

\begin{abstract}
Authors' contributions
PJ and PY were the primary physicians taking care of our patient and contributed to data collection and drafting of the manuscript. PS, the pathologist consultant, performed the histological examination of skin, revised the manuscript and prepared the figures of pathological findings. WC, the neurologist consultant, analyzed and interpreted the neurological data. YC, the hematologist consultant, analyzed and interpreted the data, and was a major contributor in writing the discussion and revision of the manuscript. All authors read and approved the final manuscript.
\end{abstract}

\section{Competing interests}

The authors declare that they have no competing interests.

Received: 17 May 2010 Accepted: 20 January 2011

Published: 20 January 2011

\section{References}

1. Sukpanichnant S, Visuthisakchai S: Intravascular lymphomatosis: a study of 20 cases in Thailand and a review of the literature. Clin Lymphoma Myeloma 2006, 6:319-328.
2. Nakamura S, Ponzoni M, Campo E: Intravascular large B-cell lymphoma. In WHO Classification of Tumours of Haematopoietic and Lymphoid Tissues. 4 edition. Edited by: Swerdlow SH, Campo E, Harris NL, Jaffe ES, Pileri SA, Stein H, Thiele J, Vardiman JW. Lyon, France: IARC Press; 2008:252-253.

3. Zuckerman D, Seliem R, Hochberg E: Intravascular lymphoma: the oncologist's "great imitator". Oncologist 2006, 11:496-502.

4. Ferreri AJ, Campo E, Seymour JF, Willemze R, llariucci F, Ambrosetti A, Zucca E, Rossi G, López-Guillermo A, Pavlovsky MA, Geerts ML, Candoni A, Lestani M, Asioli S, Milani M, Piris MA, Pileri S, Facchetti F, Cavalli F, Ponzoni M, International Extranodal Lymphoma Study Group (IELSG): Intravascular lymphoma: clinical presentation, natural history, management and prognostic factors in a series of 38 cases, with special emphasis on the 'cutaneous variant'. Br J Haematol 2004, 127:173-183.

5. Martusewicz-Boros M, Wiatr E, Radzikowska E, Roszkowski-Sliz K, Langfort R: Pulmonary intravascular large B-cell lymphoma as a cause of severe hypoxemia. J Clin Oncol 2007, 25:2137-2139.

6. Kakumitsu H, Higuchi M, Tanaka K, Shibuya T: Nephrotic syndrome in a patient with intravascular lymphomatosis. Intern Med 2003, 42:98-101.

7. Bhagwati NS, Oiseth SJ, Abebe LS, Wiernik PH: Intravascular lymphoma associated with hemophagocytic syndrome: a rare but aggressive clinical entity. Ann Hematol 2004, 83:247-250.

8. Von Kempis J, Köhler G, Herbst EW, Peter HH: Intravascular lymphoma presenting as symmetric polyarthritis. Arthritis Rheum 1998, 41:1126-1130

9. Bauer A, Perras B, Sufke S, Horny HP, Kreft B: Myocardial infarction as an uncommon clinical manifestation of intravascular large cell lymphoma. Acta Cardiol 2005, 60:551-555.

10. Gill S, Melosky B, Haley L, ChanYan C: Use of random skin biopsy to diagnose intravascular lymphoma presenting as fever of unknown origin. Am J Med 2003, 114:56-58.

11. Asada N, Odawara J, Kimura S, Aoki T, Yamakura M, Takeuchi M, Seki R, Tanaka A, Matsue K: Use of random skin biopsy for diagnosis of intravascular large B-cell lymphoma. Mayo Clin Proc 2007, 82:1525-1527.

12. Matsue K, Asada N, Takeuchi M, Yamakura M, Kimura S, Odawara J, Aoki T: A clinicopathological study of 13 cases of intravascular lymphoma: experience in a single institution over a 9-yr period. Eur $\mathrm{J}$ Haematol 2008, 80:236-244.

doi:10.1186/1752-1947-5-24

Cite this article as: Jitpratoom et al.: Progressive multifocal cerebral infarction from intravascular large B cell lymphoma presenting in a man: a case report. Journal of Medical Case Reports 2011 5:24.

\section{Submit your next manuscript to BioMed Central and take full advantage of:}

- Convenient online submission

- Thorough peer review

- No space constraints or color figure charges

- Immediate publication on acceptance

- Inclusion in PubMed, CAS, Scopus and Google Scholar

- Research which is freely available for redistribution

Submit your manuscript at www.biomedcentral.com/submit 